\title{
Reversible posterior leukoencephalopathy associated with chronic graft-versus-host disease: A case report
}

\author{
JINBEI YU, LICHAO SUN and WEIHONG LIN \\ Epilepsy Center, Department of Neurology, The First Hospital of Jilin University, Changchun, Jilin 130021, P.R. China
}

Received December 13, 2014; Accepted January 14, 2016

DOI: $10.3892 /$ etm.2016.3240

\begin{abstract}
The present study describes the clinical manifestations, magnetic resonance imaging (MRI) features and treatments of a 22-year-old male patient diagnosed with reversible posterior leukoencephalopathy syndrome (RPLS) associated with graft-versus-host disease (GVHD) 7 months after a haploid hematopoietic stem cell transplantation. The patient was admitted to hospital after falling unconscious. Head MRI demonstrated abnormal signals in the bilateral, frontal, parietal, temporal and occipital lobes, consistent with reversible posterior leukoencephalopathy syndrome (RPLS). Based on a detailed diagnosis, the response to treatment and follow-up, it was concluded that RPLS was closely associated with chronic graft-versus-host disease in the patient. The present case report is described in order to increase the awareness of RPLS.
\end{abstract}

\section{Introduction}

Reversible posterior leukoencephalopathy syndrome (RPLS) was first reported by Hinchey et al (1) in 1996, and is associated with malignant hypertension, pregnancy-eclampsia, severe kidney disease, cancer chemotherapy and immunosuppressive therapy following organ and tissue transplantations. (2) The principal clinical manifestations of RPLS are abnormalities in the nervous system involving the white matter in the posterior portions of the cerebral hemispheres (3). Clinical characteristics include headache, visual impairment, disturbance of consciousness, mental status changes, movement disorders and convulsions (1). There are a number of causes of RPLS, including hypertensive encephalopathy, acute or chronic kidney disease, thrombotic thrombocytopenic purpura, hemolytic uremic syndrome, eclampsia, vasculitis, porphyria, blood transfusion, exposure to contrast agents, various

Correspondence to: Dr Weihong Lin, Epilepsy Center, Department of Neurology, First Hospital of Jilin University, 71 Xinmin Street, Changchun, Jilin 130021, P.R. China

E-mail: linweihong321@126.com

Key words: reversible posterior leukoencephalopathy, magnetic resonance imaging, graft-versus-host disease immunosuppressants, immunomodulators and chemotherapeutic drugs (4). Other possible causes include autoimmune diseases (5), collagen vascular disease, intravenous immunoglobulin infusion, application of erythropoietin, secondary hyperparathyroidism and hypercalcemia $(6,7)$.

The present study describes a case of a 22-year-old male patient in whom RPLS associated with graft-versus-host disease (GVHD) was diagnosed 7 months after a haploid hematopoietic stem cell transplant; a case of this nature is rarely reported.

\section{Case report}

This present study has been approved by the First Hospital of Jilin University Medical Ethics Committee, and consent was obtained from the patient. The 22-year-old male patient was admitted to The First Hospital of Jilin University (Changchun, China) on May 15, 2013, $1 \mathrm{~h}$ after losing consciousness. One day prior to admission, the patient had a headache and fever of unknown origin with a body temperature reaching $38.6^{\circ} \mathrm{C}$. On the day of admittance to the hospital, a tetany seizure and transitory loss of consciousness occurred for $1 \mathrm{~min}$, followed by an extended disturbance of consciousness.

The patient had a 3-year history of aplastic anemia for which he received a haploid hematopoietic stem cell transplantation 7.5 months previously, in October 2012; the patients father was the donor. The transplant conditioning regimen was busulfan/fludarabine/cyclophosphamide + antilymphocyte globulin (domestic pig), with a GVHD prevention regimen of cyclosporine + methotrexate + mycophenolate mofetil + basiliximab (Simulect). On 8 October 2012, bone marrow and umbilical cord-derived mesenchymal $\left(8 \times 10^{7}\right.$ cells $\left./ \mathrm{kg}\right)$ stem cells from the donor were transfused, followed by peripheral blood stem cells on 9 October 2012, including nucleated cells $\left(7.29 \times 10^{8}\right.$ cells $\left./ \mathrm{kg}\right)$ and $\mathrm{CD} 34^{+}$cells $\left(6.29 \times 10^{6}\right.$ cells $\left./ \mathrm{kg}\right)$. Granulocyte-colony stimulating factor was applied seven days post-transplantation, granulocytes were applied 22 days after transplantation and platelets were applied 33 days after transplantation. During this period, tacrolimus was used to replace cyclosporine as the patient presented with elevated creatinine levels. Bone marrow puncture demonstrated active hyperplasia after 44 days (erythroid, 1\%; myeloid, 86\% and lymphocytes, $12 \%$ ) and DNA identification confirmed the success of transplantation. Following transplantation, patient therapy consisted of cyclosporine, tacrolimus, erythropoietin, 
thrombopoietin and mycophenolate mofetil. Grade II GVHD appeared 2 months following the transplant in December 2012, and the patient was treated with $120 \mathrm{mg}$ methylprednisolone (Pfizer, Inc., Puurs, Belgium) and Human Immunoglobulin and $12.5 \mathrm{~g}$ human immunoglobulin (Shanxi Kangbao Biological Products Co. Ltd., Changzhi, China). Skin GVHD occurred 5 months after the transplantation in March 2013, and the patient was treated with $20 \mathrm{mg}$ basiliximab (Beijing Novartis Pharmaceutical Co., Ltd., Beijing, China) .

When the patient was admitted to hospital following a loss of consciousness in May 2013, the patient's vital signs were stable (blood pressure, $130 / 90 \mathrm{mmHg}$; moist rales heard over both lungs; heart rate, 140 beats/min with a regular rhythm; no evident noises or extra heart sounds heard during auscultation). The abdomen was soft, the liver and spleen were untouched under the ribs and there was no significant lower extremity edema. The patient was in coma with bilateral miosis and a slow pupillary response to light; the tendon reflexes remained normal and symmetrical. Kernig's sign was negative, and there was no pathological reflex. The patient was not able to cooperate with any further neurological examinations.

Head magnetic resonance imaging (MRI) and magnetic resonance angiography (MRA) were performed on May 22, 2013. Scattered patchy or flaky areas with slight hypointense T1 and slightly longer T2 signals with obscure boundaries were observed in the bilateral frontal lobe, parietal lobe, temporal lobe and occipital lobe. Flair images revealed a high signal intensity, and diffusion-weighted imaging (DWI) revealed low signal intensity, in particular in the bilateral superior occipital lobes (Fig. 1). The MRA was normal.

Blood laboratory test results, received on 16 May 2013, were as follows: White blood cells, $3.26 \times 10^{9}$ cells/1; platelets, $15 \times 10^{9}$ cells/1; erythrocytes, $2.82 \times 10^{12}$ cells $/ 1$; hemoglobin, $101.0 \mathrm{~g} / \mathrm{l}$; hematocrit, $0.303 \mathrm{l} / 1$; mean corpuscular volume, $107.4 \mathrm{fl}$; plateletcrit, $0.012 \%$; percentage of neutrophils, $37.7 \%$; percentage of lymphocytes, $56.6 \%$; neutrophils, $1.23 \times 10^{9}$ cells/1; and eosinophils, $0.02 \times 10^{9}$ cells $/ 1$. Other laboratory test results were as follows: Alanine aminotransferase, $83 \mathrm{IU} / \mathrm{l}$; aspartate aminotransferase, $68 \mathrm{IU} / 1$; albumin, $23 \mathrm{~g} / \mathrm{l}$; gamma-glutamyl transpeptidase, $243 \mathrm{IU} / 1$; lactate dehydrogenase, $511 \mathrm{IU} / 1$; valley threonine dehydrogenase, $32 \mathrm{U} / 1$; urea, $11.6 \mathrm{mmol} / \mathrm{l}$; and glucose, $11.5 \mathrm{mmol} / \mathrm{l}$. The blood culture was positive for methicillin-resistant Staphylococcus aureus. There were no obvious abnormal test results obtained for blood clotting or ions.

Following admission into hospital, an endotracheal intubation was inserted and the patient was supported by mechanical assist/control ventilation on a US Newport E360 ventilator (tidal volume, $600 \mathrm{ml}$; oxygen, $40 \%$; positive end-expiratory pressure, $7 \mathrm{~cm}$; inhale:exhale, 1:2). In addition, the patient was administered a blood transfusion, methylprednisolone, mannitol, human immunoglobulin, torasemide and meropenem. Four days after admission into hospital, the patient gradually regained consciousness and self-respiration, and his body temperature returned to normal; however, the patient had blurred vision in his left eye. Rehydration, hormonal and anti-infection treatments were continued. The patients vision improved with the above treatments, but the left eye remained with poorer vision compared with the right eye. Six days after admission, the patient returned to normal consciousness and was extubated; he recovered and was discharged 9 days after admission into hospital. Upon discharge from the hospital, the patient was conscious without any other positive neurological signs; however, the sight in the left eye remained poor.

An MRI of the head was performed on 3 June 2013, 10 days after discharge from hospital. Patchy abnormal signal intensities were observed in the left superior occipital; on the T1 weighted image (WI) the signal intensity was slightly low with punctate areas of high intensity at the edges, on the T2WI the signal intensity was high, and on the water- and fat-suppressed images the signal intensity was high. There were significant improvements observed in the lesions since the day of admission into hospital (Fig. 2). After 8 months, the patient had no obvious abnormalities other than poor sight in his left eye. An MRI of the head, performed on 23 January 2014, revealed a patchy area of slightly increased $\mathrm{T} 1$ and $\mathrm{T} 2$ signal intensities in the left parietal lobe area, and a slightly increased signal on the water- and fat-suppressed images. No obvious abnormalities were detected on the DWI images. A slightly increased signal intensity with fuzzy boundaries was observed on the apparent diffusion coefficient (ADC) images and the original lesion was no longer observed (Fig. 3).

\section{Discussion}

There is currently no full understanding regarding the pathogenesis of RPLS. One possible mechanism may be the failure of cerebrovascular autoregulation; patients with RPLS who have high blood pressure have developed cerebrovascular autoregulation disorders which have caused vasogenic cerebral edema (5). Cerebrovascular autoregulation is a form of neurogenic regulation; the sympathetic nervous system can help sustain self-regulation of the cerebral vasculature when there is an abrupt increase in blood pressure (8). Blood of the posterior hemisphere is supplied by the posterior cerebral blood circulation of the vertebrobasilar system, which possesses fewer sympathetic nerves compared with the carotid circulation arterial system. Therefore, the posterior white matter is more prone to develop vasogenic cerebral edema caused by increased vascular permeability (5). When the blood pressure rises and overwhelms the ability of the cerebrovascular system to autoregulate, increased vascular permeability and leakage of plasma and red blood cells eventually results in vasogenic cerebral edema $(6,7)$. Hinchey et al (1) hypothesized that RPLS may be related to brain capillary leak syndrome caused by the toxic effects of immunosuppressive drugs to endothelial cells. This would explain why eclampsia patients, who have no hypertension or mild hypertension, develop RPLS. However, there are other etiological factors involved in the development of RPLS, such as fluid retention and damage to the blood-brain barrier (1).

RPLS has no specific clinical symptoms. Distinct imaging characteristics primarily involve the cerebral hemisphere occipital lobe, subcortical white matter of the posterior parietal temporal lobe, the cerebellum and the brain stem. Computed tomography (CT) images record low signal intensities, long T1 and T2 signals are typically observed on MRI and flair images record high signals (9). DWI images typically record low or equal signal intensities, and signals on ADC images are frequently high (10-13). Lesions are reversible and may 
A

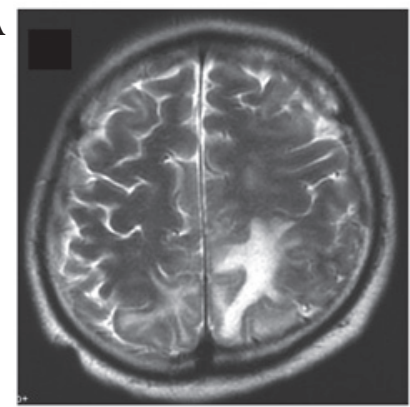

B

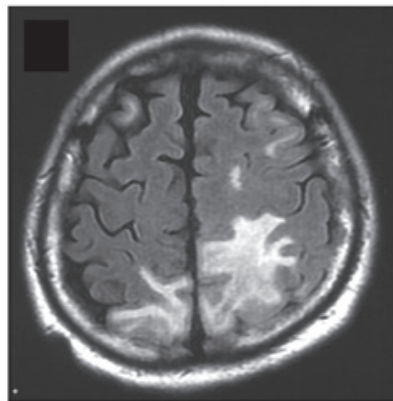

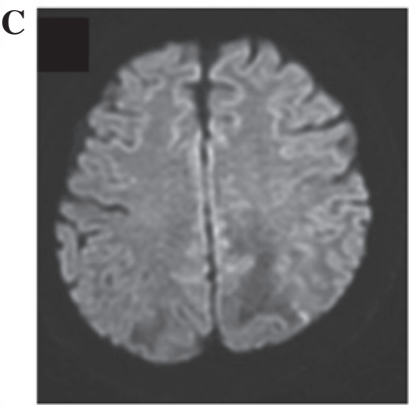

Figure 1. Brain magnetic resonance images captured on May 22, 2013. (A) Scattered patchy or flaky areas of slightly longer T2 signals with obscure boundaries in the bilateral frontal lobe, parietal lobe, temporal lobe, and occipital lobe, (B) high signal on Flair images, and (C) low signal on diffusion-weighted images
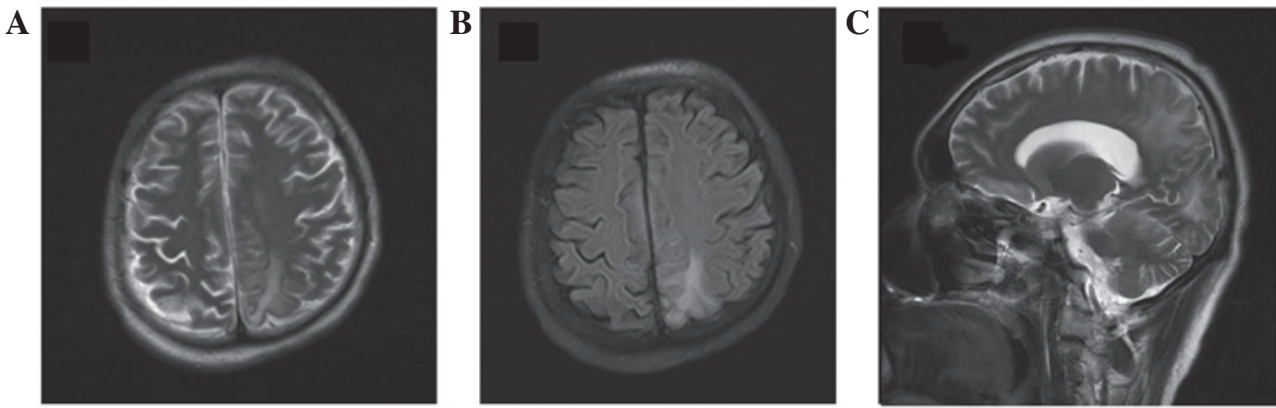

Figure 2. Brain magnetic resonance images captured on June 3, 2013. (A) Long T2 signal in the left occipital lobe and (B) high signal on Flair images, (C) with the abnormal area significantly reduced from previously.
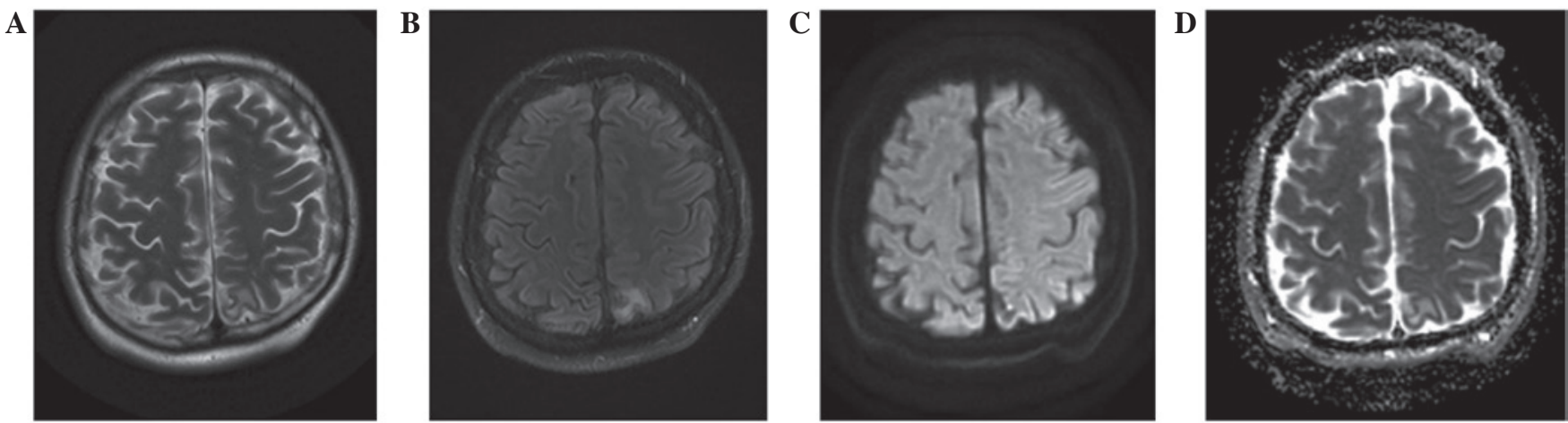

Figure 3. Brain magnetic resonance images captured on January 23, 2014. (A) There were patchy areas of slightly increased T2 signal in the left parietal lobe, (B) slightly high signal with fuzzy boundaries on the water- and fat-suppressed images, (C) no obvious abnormalities in diffusion-weighted images, and (D) slightly high signal on the apparent diffusion coefficient images.

disappear completely after a period of treatment, and as a result the prognosis is positive (1).

Teive et al (14) reported eight cases of RPLS associated with bone marrow transplantation. The patients were treated with cyclosporine A following an allogeneic bone marrow transplantation or to treat severe aplastic anemia. When the patients were given lower doses of cyclosporine A, or when the drug was withdrawn, the symptoms and neuroimaging abnormalities associated with RPLS reversed and improved. Thus, RPLS may be associated with cyclosporine A neurotoxicity. Drugs that may induce RPLS include antineoplastic agents, such as bevacizumab (15), immunosuppressive agents (4), such as tacrolimus (16), human immunoglobulin for intravenous injection, linezolid and erythropoietin. Treatments for drug-induced RPLS primarily include withdrawing the suspected drug and ensuring rehydration with a timely control of hypertension and convulsions. Won et al (17) reported eight cases of RPLS associated with childhood hematology and oncology diseases, including one case of aplastic anemia. In the case of aplastic anemia, chemotherapy and surgery were considered to contribute towards the development of RPLS more than immunosuppressive agents.

The patient in the present study had an acute onset of a headache, fever, convulsions, visual disturbances and unconsciousness, and the radiographic changes were consistent with RPLS. The patient had received haploid hematopoietic stem cell transplantation in order to treat aplastic anemia 7 months prior to his admission into hospital. A large quantity of immunosuppression therapy was performed prior to the transplantation. Postoperative cyclosporine, tacrolimus, 
erythropoietin, thrombopoietin, and mycophenolate mofetil therapy was administered, and the immunosuppressants were administered throughout the entire course.

The risk factors of RPLS following allogeneic hematopoietic stem cell transplantation have been previously discussed in literature, and high-dose chemotherapy, immunosuppressive agents, infection or systemic inflammatory response syndrome (SIRS) and vascular endothelial cell damage caused by GVHD are considered to be risk factors $(5,18,19)$. GVHD is a multi-system disease affecting the skin, esophagus, stomach, and liver following bone marrow transplantation and is one of the primary causes of mortality (20). GVHD may be acute, occurring within 3 months after the transplant, or chronic, occurring 3 months after the transplant. The clinical manifestations are complex; acute GVHD is related to inflammatory cytokines and can result in endothelial cell damage $(5,21,22)$, thus making it a risk factor for the onset of RPLS.

Chronic GVHD will increase endothelial cell damage $(5,21-23)$. The pathogenesis of chronic GVHD is similar to the pathogenesis of autoimmune diseases, such as scleroderma, and it can be hypothesized that autoimmune diseases induce RPLS (21-23). In the present study, the patient developed RPLS following the onset of chronic GVHD. Basiliximab was administered prior to the stem cell transplantation, but did not induce RPLS at that time.

Pruitt et al (24) reported that the central nervous system may be a target of GVHD. Although GVHD rarely involves the central nervous system, it can be affected in patients with chronic GVHD (24). Based on the above analysis, it can be concluded that RPLS and chronic GVHD were closely related in the patient in the present study. Considering that the patient experience an early onset of fever, it is likely that the infection-induced GVHD resulted in the development of RPLS.

In conclusion, a rare case of reversible posterior leukoencephalopathy, which was associated with chronic graft-versus-host disease, was reported in the present study in order to increase awareness of the disease. The typical clinical presentation and imaging features of RPLS are useful when reaching a diagnosis. Clinicians who encounter this syndrome should have a complete understanding of the diagnostic criteria of the disease, and further pathological studies are required in order to further develop the understanding of RPLS.

\section{References}

1. Hinchey J, Chaves C, Appignani B, Breen J, Pao L, Wang A, Pessin MS, Lamy C, Mas JL and Caplan LR: A reversible posterior leukoencephalopathy syndrome. N Engl J Med 334: 494-500, 1996.

2. Lamy C, Oppenheim C and Mas JL: Posterior reversible encephalopathy syndrome. Handb Clinical Neurol 121: 1687-1701, 2014.

3. Lamy C, Oppenheim C, Meder JF and Mas JL: Neuroimaging in posterior reversible encephalopathy syndrome. J Neuroimaging 14: 89-96, 2004.

4. Fugate JE, Claassen DO, Cloft HJ, Kallmes DF, Kozak OS and Rabinstein AA: Posterior reversible encephalopathy syndrome: Associated clinical and radiologic findings. Mayo Clin Proc 85: 427-432, 2010.

5. Bartynski WS: Posterior reversible encephalopathy syndrome, part 2: Controversies surrounding pathophysiology of vasogenic edema. AJNR Am J Neuroradiol 29: 1043-1049, 2008.
6. Covarrubias DJ, Luetmer PH and Campeau NG: Posterior reversible encephalopathy syndrome: Prognostic utility of quantitative diffusion-weighted MR images. AJNR Am J Neuroradiol 23: 1038-1048, 2002.

7. Hunt SM, McKenna SP, McEwen J, Backett EM, Williams J and Papp E: A quantitative approach to perceived health status: A validation study. J Epidemiol Community Health 34: 281-286, 1980.

8. ter Laan M, van Dijk JM, Elting JW, Staal MJ and Absalom AR: Sympathetic regulation of cerebral blood flow in humans: A review. Br J Anaesth 111: 361-367, 2013.

9. Bartynski WS: Posterior reversible encephalopathy syndrome, part 1: Fundamental imaging and clinical features. AJNR Am J Neuroradiol 29: 1036-1042, 2008.

10. Casey SO, Sampaio RC, Michel E and Truwit CL: Posterior reversible encephalopathy syndrome: Utility of fluid-attenuated inversion recovery MR imaging in the detection of cortical and subcortical lesions. AJNR Am J Neuroradiol 21: 1199-1206, 2000.

11. Schwartz RB, Feske SK, Polak JF, DeGirolami U, Iaia A, Beckner KM, Bravo SM, Klufas RA, Chai RY and Repke JT: Preeclampsia-eclampsia: Clinical and neuroradiographic correlates and insights into the pathogenesis of hypertensive encephalopathy. Radiology 217: 371-376, 2000.

12. Engelter ST, Provenzale JM and Petrella JR: Assessment of vasogenic edema in eclampsia using diffusion imaging. Neuroradiology 42: 818-820, 2000.

13. Provenzale JM, Petrella JR, Cruz LC Jr, Wong JC, Engelter S and Barboriak DP: Quantitative assessment of diffusion abnormalities in posterior reversible encephalopathy syndrome. AJNR Am J Neuroradiol 22: 1455-1461, 2001.

14. Teive HA, Brandi IV, Camargo CH, Bittencourt MA, Bonfim CM, Friedrich ML, de Medeiros CR, Werneck LC and Pasquini R: Reversible posterior leucoencephalopathy syndrome associated with bone marrow transplantation. Arq Neuropsiquiatr 59: 784-789, 2001.

15. Glusker P, Recht L and Lane B: Reversible posterior leukoencephalopathy syndrome and bevacizumab. N Engl J Med 354: 980-982; Disscussion 980-982, 2006

16. Wong R, Beguelin GZ, de Lima M, Giralt SA, Hosing C, Ippoliti C, Forman AD, Kumar AJ, Champlin R and Couriel D: Tacrolimus-associated posterior reversible encephalopathy syndrome after allogeneic haematopoietic stem cell transplantation. Br J Haematol 122: 128-134, 2003.

17. Won SC, Kwon SY, Han JW, Choi SY and Lyu CJ: Posterior reversible encephalopathy syndrome in childhood with hematologic/oncologic diseases. J Pediatr Hematol Oncol 31: 505-508, 2009

18. Bartynski WS, Zeigler ZR, Shadduck RK and Lister J: Pretransplantation conditioning influence on the occurrence of cyclosporine or FK-506 neurotoxicity in allogeneic bone marrow transplantation. AJNR Am J Neuroradiol 25: 261-269, 2004.

19. Fukuyama T, Tanaka M, Nakazawa Y, Motoki N, Inaba Y, Higuchi T and Koike K: Prophylactic treatment for hypertension and seizure in a case of allogeneic hematopoietic stem cell transplantation after posterior reversible encephalopathy syndrome. Pediatr Transplant 15: E169-E173, 2011.

20. Blazar BR and Murphy WJ: Bone marrow transplantation and approaches to avoid graft-versus-host disease (GVHD). Philos Trans R Soc Lond B Biol Sci 360: 1747-1767, 2005.

21. Bartynski WS, Tan HP, Boardman JF, Shapiro R and Marsh JW: Posterior reversible encephalopathy syndrome after solid organ transplantation. AJNR Am J Neuroradiol 29: 924-930, 2008.

22. Bartynski WS, Zeigler ZR, Shadduck RK and Lister J: Variable incidence of cyclosporine and FK-506 neurotoxicity in hematopoeitic malignancies and marrow conditions after allogeneic bone marrow transplantation. Neurocrit Care 3: 33-45, 2005.

23. Rouquette-Gally AM, Boyeldieu D, Gluckman E, Abuaf N and Combrisson A: Autoimmunity in 28 patients after allogeneic bone marrow transplantation: Comparison with Sjögren syndrome and scleroderma. Br J Haematol 66: 45-47, 1987.

24. Pruitt AA, Graus F and Rosenfeld MR: Neurological complications of transplantation: Part I: Hematopoietic cell transplantation. Neurohospitalist 3: 24-38, 2013. 